\title{
Adenosine Deaminase Activities in Sera, Lymphocytes and Granulocytes in Patients with Cutaneous Leishmaniasis
}

\section{Ozcan Erel/ ${ }^{+}$, Abdurrahim Kocyigit, Mehmet Salih Gurel*, Vedat Bulut**, Adnan Seyrek***, Yuksel Ozdemir****}

\author{
Department of Clinical Biochemistry *Department of Dermatology ***Department of Microbiology and \\ Parasitology, Medical Faculty, Harran University, Sanliurfa, Turkey **Department of Clinical Microbiology, \\ Medical Faculty, Firat University, Elazig, Turkey **** Department of Clinical Biochemistry, \\ Medical Faculty, Gaziantep University, Gaziantep, Turkey
}

Adenosine deaminase (ADA) activities in sera, lymphocytes and granulocytes in patients with cutaneous leishmaniasis were investigated and compared with control groups. Fifty patients and 50 healthy individuals were studied. The clinical diagnosis was parasitologically confirmed by culture and Giemsa stain. ADA activities were measured by colorimetric method. Serum ADA activities $37.80 \pm 11.90,18.28$ $\pm 6.08 \mathrm{IU} / \mathrm{L}(\mathrm{p}<0.0001)$, lymphocyte specific ADA activities $14.90 \pm 7.42,8.38 \pm 7.42 \mathrm{U} / \mathrm{mg}$ protein ( $p$ $=0.04$ ), granulocyte specific ADA activities $1.15 \pm 0.73,1.09 \pm 0.67 \mathrm{U} / \mathrm{mg}$ protein $(p>0.05)$ were found in patients and control groups, respectively. ADA activity increases in some infectious diseases were cell mediated immune mechanisms are dominant. In cutaneous leishmaniasis, lymphokine-mediated macrophage activity is the main effector mechanism. Increase in serum and lymphocyte ADA activities in patients with cutaneous leishmaniasis may be dependent on and reflects the increase in phagocytic activity of macrophages and maturation of T-lymphocytes.

Key words: adenosine deaminase - leishmaniasis

Adenosine deaminase (ADA, Adenosine aminohydrolase, E.C. 3.5.4.4.) is an enzyme involved in the catabolism of purine bases, capable of catalyzing the deamination of adenosine, forming inosine in the process (Fox \& Kelley 1978). Its main physiologic activity is related to lymphocytic proliferation and differentiation.

The enzyme activity increases substantially during mitogenic (Hovi et al. 1976) and antigenic responses of lymphocytes and, conversely, lymphocyte blastogenesis is inhibited by inhibitors of ADA (Carson \& Seegmiller 1976). ADA activity is higher in T-lymphocytes (Huang et al. 1976, Shore et al. 1981) with increased activity in the immature or undifferentiated stages. As a marker of cellular immunity, its plasma activity is found to be elevated in those diseases in which there is a cell-mediated immune response (Galanti et al. 1981, Piras et al. 1982).

Leishmania are dimorphic protozoa that spend part of their life cycle in a vector and partly in a mammalian host. The extracellular promastigote form of the parasite develops in the sand fly in-

\footnotetext{
${ }^{+}$Corresponding author. Fax : +90-414-3151181. E-mail: gurelm@doruk.net.tr

Received 19 November 1997

Accepted 17 April 1998
}

oculates into human (or other mammalian) skin. The promastigote subsequently undergoes phagocytosis by a macrophage and converts to the obligate intracellular amastigote stage (Chang \& Chang 1985, Sies 1987). Macrophage is the exclusive host cell of the intracellular parasite Leishmania (Locksley \& Louis 1992).

Cutaneous leishmaniasis usually affects unclothed parts of body easily bitten by the sand fly vector, including face, neck and arms. After an incubation period of one week to three months in average, a red papule appears, which enlarges to a plaque or nodule. It may heal spontaneously in about one year. The clinical manifestations are dependent both on the infecting species of Leishmania and on the immune response of the host (Liew \& O'Donnel 1993, Grevelink \& Lerner 1996).

Since relationship exists between ADA activity and the cell mediated immune response, and there is no data about ADA activity in cutaneous leishmaniasis, we aimed to determine serum, lymphocyte and granulocyte ADA activities of patients with cutaneous leishmaniasis and compare with control groups.

\section{MATERIALS AND METHODS}

Subjects - Patients came from Leishmania Eradication Center of Sanliurfa Region which is an hyperendemic area for leishmaniasis in the southeastern Anatolia of Turkey. Subjects were 50 
patients and 50 healthy individuals aged of 10-30 years from the same area. All participants gave informed consent for the present study.

The clinical diagnosis was confirmed by laboratory demonstration of the parasite in the lesions by direct smears. Lesions were cleaned with ethanol, and punctured at the margins of the lesion with a sterile lancet. Exudating material was smeared, dried in air and fixed by methanol. The smears were stained with Giemsa's stain for examination by light microscopy. Microscopic diagnosis was made when amastigotes were identified in the smears. In order to confirm the diagnosis, the material was also cultured on Novy Mac-Neal-Nicolle (NNN) medium for up to three weeks to detect the leishmanial promastigotes. After diagnostic procedure, blood sample was withdrawn to measure serum, lymphocyte and granulocyte ADA activity.

Measurement of serum, lymphocyte and granulocyte ADA activity - Ten ml venous blood was withdrawn. Four ml of blood samples, were transferred into tubes, after centrifugation at $900 \times \mathrm{x}$ for $10 \mathrm{~min}$, serum was separated for serum ADA activity measurement. Six ml of blood samples were transferred into tubes containing heparin. Lymphocyte and granulocyte were separated by Ficoll gradient centrifugation technique (Sigma Chemical Co., St. Louis, USA) (Boyum 1968a,b). The contaminating red blood cells were removed by hypotonic lysis.

The separated lymphocytes and granulocytes were washed three times with Hank's balanced salt solution (HBSS). The suspension of cells in HBSS solution was centrifuged at $800 \mathrm{x} g$ for $10 \mathrm{~min}$, and the supernatants were discarded. The sediment was resuspended in $1 \mathrm{ml}$ of distilled water and the suspensions of cells were frozen and thawed six times. The centrifuged supernatants were then analyzed for enzyme activities and protein determination. Protein estimation was performed using the method of Lowry (Lowry et al. 1951) and results were expressed in $\mathrm{mg} / \mathrm{l}$.

Serum, lymphocyte and granulocyte ADA activities were determined at $37^{\circ} \mathrm{C}$ according to the method of Giusti and Galanti (1984) based on the
Bertholet reaction, that is, the formation of colored indophenol complex from ammonia liberated from adenosine and quantified spectrophotometrically. One unit of ADA is defined as the amount of enzyme required to release $1 \mathrm{mmol}$ of ammonia/min from adenosine at standard assay condition. Results were expressed as international unit of enzyme activity of serum and as unit of specific enzyme activity/mg protein of lymphocyte and granulocyte (Storch et al. 1981).

Statistical analyses - Student's $t$ test and correlation analyses tests were performed. A computer program that is SPSS for Windows Release 6.0 was used for statistical analyses.

\section{RESULTS}

Measured serum, lymphocyte and granulocyte ADA activities of patients and control groups are shown in Table. Significant differences between serum and lymphocyte ADA activities of patients and control groups were found (Figs 1-2). However the difference between granulocytic specific ADA activities of patients and controls was not significant. There were positive correlations among ADA activities of serum, lymphocyte and granulocyte and, the duration of the disease, total area and sizes of lesions, but they were not significant statistically. The mean duration of the disease was $5.32 \pm 2.78$ months, and the mean area of lesions was $3.52 \pm 3.10 \mathrm{~cm}^{2}$.

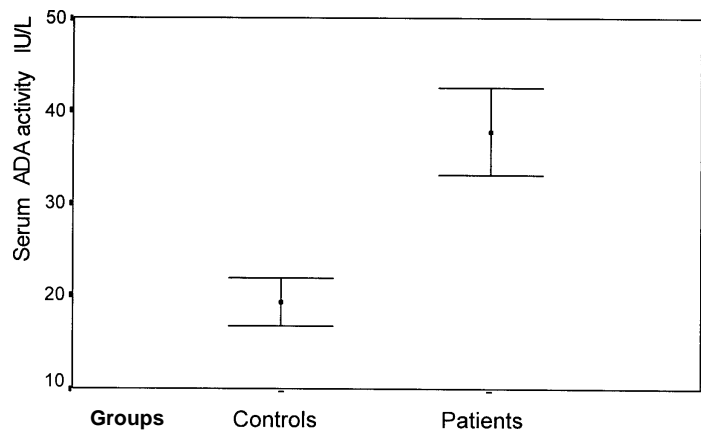

Fig. 1: serum adenosine deaminase (ADA) activities of control and patients groups (mean $\pm S D)$. Very important difference between control and patients groups $(\mathrm{p}<0.0001)$.

TABLE

Serum, lymphocyte and granulocyte adenosine deaminase (ADA) activities in patients with cutaneous leishmaniasis and control groups

\begin{tabular}{lccc}
\hline ADA activity & $\begin{array}{c}\text { Control groups } \\
(n=50)\end{array}$ & $\begin{array}{c}\text { Patient groups } \\
(n=50)\end{array}$ & $p^{a}$ \\
\hline Serum (IU/l) & $18.28 \pm 6.08$ & $37.80 \pm 11.98$ & $<0.0001$ \\
Lymphocyte (IU/mg protein) & $8.38 \pm 7.42$ & $14.90 \pm 11.40$ & 0.04 \\
Granulocyte (IU/mg protein) & $1.15 \pm 0.73$ & $1.09 \pm 0.67$ & 0.32 \\
\hline
\end{tabular}

Values are mean $\pm \mathrm{SD} ; a$ : values less than 0.05 is significant obtained from student's $t$ test. 


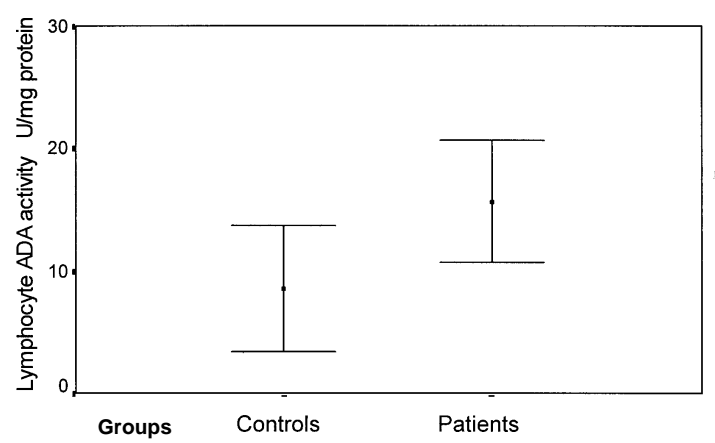

Fig. 2: lymphocyte adenosine deaminase (ADA) activities of control and patients groups $($ mean $\pm S D)$. Significant difference between control and patients groups $(\mathrm{p}=0.04)$.

\section{DISCUSSION}

ADA is an enzyme capable of catalyzing the catabolism of purine bases and whose principal biologic activity is detected in $\mathrm{T}$ lymphocytes (Sullivan et al. 1977). The role of this enzyme in cellular immune function was highlighted following the discovery of reduced levels in patients with severe combined immunodeficiency (Van der weyden \& Kelley 1977).

The ADA activity originates from the action of principal isoenzymes, ADA-1 and ADA-2. ADA-1 is present in all tissues and is essential for an efficient immune response. The congenital absence of ADA-1 in the lymphocytes and erythrocytes causes severe combined immunodeficiency syndrome. ADA-2 is not related to severe combined immunodeficiency syndrome. It is found only in monocytes and macrophages and not in other cells and is released by these cells when they are stimulated by the presence of live microorganisms in their interior (Zuckerman et al. 1980). The predominant isoenzyme in the sera is ADA-2 in all of infectious diseases (Ungerer et al. 1992). However, the reason why ADA-2 is the predominant serum enzyme still has to be determined. It has strongly been suggested that serum ADA activity reflects monocyte/macrophage activity or turnover in different diseases (Gakis et al. 1989, Ungerer et al. 1992, Stancikova \& Rovensky 1993).

ADA has been considered as a marker of cell mediated immunity (Piras et al. 1978, Baganha et al. 1990). Increased serum ADA activities have been observed in many infectious diseases caused by microorganisms infecting mainly the macrophages, in tuberculosis, leprosy, brucellosis, and in human deficiency virus (HIV) infection. Interestingly, Gakis et al. (1991) observed high ADA activities in the sera of three patients with visceral leishmaniasis (kala azar).

Very little data is presented about granulocytic specific ADA activity. We found no significant difference between granulocytic specific ADA activities of patients and control groups. ADA activity is higher in T-cells than in B-lymphocytes, and varies during differentiation of T-lymphocytes with increased activity found to be elevated in diseases in which there is a cell mediated immune response (Huang et al. 1976, Shore et al. 1981). High lymphocyte ADA activities have been observed in tuberculosis, leprosy, salmonellosis and in subjects with renal allograft transplants undergoing acute graft rejection where cell mediated immunity is stimulated (Yasmineh et al. 1977, Ocana et al. 1983). We found increased lymphocytic specific ADA activity in patients with cutaneous leishmanasis.

During both experimental and human leishmanial infections, $T$ cells stimulated by antigen proliferate and produce lymphokines capable of activating macrophages. Since Leishmania are obligate intracellular parasites of macrophages, it is generally assumed that the main effector mechanism controlling parasite growth is lymphokinemediated macrophage activation. A strong correlation has been observed between production of interferon gamma (IFN-g) and phagocytic activity of macrophages in leishmaniasis (Murray et al. 1982). It has been shown that IFN-gis synthesized by the T helper type 1 (Th1) subsets of CD4 T lymphocytes (Steven \& Scoot 1993).

It was assumed for a long time that reactive oxygen intermediates such as superoxide and hydrogen peroxide were the major killing mechanism. However, recent studies from several laboratories show that nitric oxide is in fact the principal effector mechanism in cutaneous leishmaniasis. It has been shown that there are positive correlation between macrophage nitric oxide production and Th1 cytokines such as IFN-g, interleukin (IL) 2 and, negative correlation between macrophage nitric oxide production and $\mathrm{T}$ helper type 2 (Th2) cytokines such as IL- 4, IL-5 and IL-10.

In our opinion, the increasing serum ADA activity in patients with cutaneous leishmaniasis may be a reflect of phagocytic activity of macrophages. On the other hand, the increasing lymphocytic specific ADA activity may also be reflecting the differentiation of lymphoblastoid cells to specially Th1 cells. Positive correlation between serum and lymphocyte ADA activities may be reflecting the induction of phagocytosis of macrophages by IFNgand IL-2 which are synthesized by Th1 cells.

According to our knowledge that is the first report about serum, lymphocyte and granulocyte ADA activities in cutaneous leishmaniasis. To explain the cause and mechanisms of increased levels of ADA activities further studies are requested. 


\section{REFERENCES}

Baganha MF, Pego A, Lima MA, Gaspar EV, Pharm B, Carderio AR 1990. Serum and pleural adenosine deaminase: correlation with lymphocytic populations. Chest 97: 605-610.

Boyum A 1968a. A one stage procedure for isolation of granulocytes and lymphocytes from human blood. Scandinavian J Clin Lab Invest 21 (Suppl. 97): 3150.

Boyum A 1968b. Isolation of mononuclear cells and granulocytes from humans. Scandinavian J Clin Lab Invest 21 (Suppl. 97): 77-89.

Carson DA, Seegmiller JE 1976. Effect of adenosine deaminase inhibition upon human lymphocyte blastogenesis. J Clin Invest 57: 274-282.

Chang CS, Chang KP 1985. Heme-requirement and acquisition by extracellular and intracellular stages of Leishmania mexicana amozonensis. Mol Biochem Parasitol 16: 267-276.

Fox IH, Kelley WN 1978. The role of adenosine deaminase and 2'-deoxyadenosine in mammalian cells. Ann Rev Biochem 47: 655-686.

Gakis G, Calia GM, Naitana AG, Pirino D, Serru G 1989. Serum adenosine deaminase activity in HIV positive subjects. A hypothesis on the significance of ADA-2. Panminerva Med 31:107-113.

Gakis G, Calia GM, Naitana AG, Ortu AN, Contu A 1991. Serum and pleural adenosine deaminase activity. Chest 99: 1555-1556.

Galanti B, Nardiello S, Russo M, Fiorentino F 1981. Increased lymphocyte adenosine deaminase in typhoid fever. Scandinavian J Infect Dis 13: 47-50.

Giusti G, Galanti B 1984. Adenosine deaminase: colorimetric method, p. 315-323. In HU Bergmeyer, Methods of Enzymatic Analysis, Vol. 4, 3rd ed., Verlac Chemie, Weinheim.

Grevelink SA, Lerner EA 1996. Leishmaniasis. J Am Acad Dermatol 32: 257-272.

Hovi T, Smyth JF, Allison AC, Williams SC 1976. Role of adenosine deaminase in lymphocyte proliferation. Clin Exp Immunol 23: 395-403.

Huang A, Logve GL, Engelbrecht H 1976. Two biochemical markers in lymphocyte subpopulations. $\mathrm{Br}$ J Haematol 34: 631-638.

Liew FY, O’Donnel CA 1993. Immunology of leishmaniasis. Adv Parasitol 32: 161-259.

Locksley RM, Louis JA 1992. Immunology of leishmaniasis. Curr Op Immunol 4: 413-414.

Lowry OH, Rosebrough NL, Farr AL, Randall RJ 1951. Protein measurement with the Folin phenol reagent.
J Biol Chem 193: 265-275.

Murray HW, Masur H, Keithly JS 1982. Cell mediated immune response in experimental visceral leishmaniasis. I. Correlation between resistance to Leishmania donovani and lymphokyne generating capacity. J Immunol 129: 344-350.

Ocana I, Jose M, Martinaz-Vazquez RM, Fernandez T, Capdevilla JA 1983. Adenosine deaminase in pleural fluids, test for diagnosis of pleural fluids. Chest 84: $51-53$

Piras MA, Gakis C, Budroni M, Andreoni G 1978. Adenosine deaminase activity in pleural effusions: an aid to differential diagnosis. $\mathrm{Br}$ Med $\mathrm{J} 2$ 2: 17511752.

Piras MA, Gakis C, Budroni M, Andreoni G 1982. Immunological studies in Mediterranean spotted fever. Lancet 1(8283): 1249.

Shore A, Dosch HM, Gelfand EW 1981. Role of adenosine deaminase in the early stage of precursor T cell maturation. Clin Exp Immunol 44: 152-155.

Sies H 1987. Antioxidant activity in cells and organs. Am Rev Respir Dis 136: 478-480.

Stancikova M, Rovensky J 1993. Effect of cyclosperin on the activity of cytidine deaminase and adenosine deaminase in the serum and polimorphonuclear leukocytes of patients with rheumatoid arthritis. Int $J$ Tiss Reac 15: 169-174.

Steven G, Scoot RP 1993. T-cell and cytokine responses in leishmaniasis. Curr Op Immunol 5: 524-531.

Storch H, Kruger W, Rotzsch W 1981. Adenosine deaminase activity in plasma and blood cells of patients with hematological and autoimmune disease. Acta Haemat 65: 183-188.

Sullivan JL, Osborne WR, Wedgwood RJ 1977. Adenosine deaminase activity in lymphocytes. $\mathrm{Br} J$ Haematol 122: 216-220.

Ungerer JP, Oosthuizen HM, Bisbort SH, Vermaak WJ 1992. Serum adenosine deaminase: isoenzymes and diagnostic applications. Clin Chem 38: 1322-1326.

Van der weyden M, Kelley WN 1977. Adenosine deaminase deficiency and severe combined immunodeficiency. Life Sciences 20:1645-1650.

Yasmineh WG, Brynes RK, Lum CT, Abbasnezhad M 1977. Adenosine deaminase in lymphocytes of normal persons, leukemic patients and kidney transplant recipients. Clin Chem 23: 2024-2029.

Zuckerman SH, Olson JM, Douglas SD 1980. Adenosine deaminase activity during in vitro culture of human peripheral blood monocytes and pulmonary alveolar macrophages. Exp Cell Res 129: 281-287. 